\title{
A DÊIXIS MEMORIAL FICTIVA E NÃO FICTIVA
}

\author{
THE FABLED AND NON-FABLED MEMORIAL DEIXIS
}

Joana Darc Oliveira Cruz Pinheiro ${ }^{1}$

\begin{abstract}
"É difícil separar a ficção da invenção, a fantasia da memória. Não há uma linha separando o que você viu do que você sonhou. A imaginação ocupa o espaço da memória."

Lygia Fagundes Telles
\end{abstract}

RESUMO: O presente artigo apresenta uma parte dos resultados de nossa pesquisa no doutorado. Investigamos o fenômeno dêitico memorial em narrativas ficcionais, revemos as concepções de dêixis memorial (FRASER; JOLY, 1980) e dêixis fictiva (FONSECA, 1992) a partir do diálogo com a Teoria do movimento do centro dêitico (ZUBIN; HEWITT, 1995). Para tal, trabalhamos com um corpus constituído por textos de três gêneros: contos, crônicas e parábolas. Defendemos a tese de que a narrativa ficcional possibilita novos campos dêiticos, pois temos nesses textos um ambiente que possibilita um uso diferencial dos elementos dêiticos, especificamente os dêiticos memoriais. Na verdade, o próprio conceito de dêixis memorial é ampliado a partir desta perspectiva, de forma diferenciada do quadro clássico de classificação destes elementos. Apresentamos, como resultado de nossa análise, o conceito de dêixis memorial fictiva.

PALAVRAS-CHAVE: Narrativa ficcional; Dêixis; Dêixis memorial.

ABSTRACT: The present article presents a part of the results of our research in the doctorate. We investigate the memorial deictic phenomenon in fictional narratives, we review the conceptions of memorial deixis (FRASER; JOLY, 1980) and fabled deixis (FONSECA, 1992) from the dialog with the Theory of the movement of the deictic center (ZUBIN; HEWITT, 1995). For this, we work with a corpus consisting of texts of three genres: short stories, chronicles and parables. We defend the thesis that the fictional narrative makes possible new deictic fields, because we have in these texts an environment that allows a differential use of the deictic elements, specifically the memorials deictic. In fact, the concept of memorial demarcation itself is broadened from this perspective, differently from the classical classification of these elements. We present, as a result of our analysis, the concept of fabled memorial deixis.

KEYWORDS: Fictional narrative; Deixis; Memorial Deixis.

\footnotetext{
${ }^{1}$ Doutora em Linguística Aplicada pela Universidade Estadual do Ceará (UECE). Professora formadora de docentes de Língua Portuguesa da Educação Básica.
} 


\section{Introdução}

Primeiramente, convém iniciar este artigo respondendo a seguinte pergunta: por que investigar a dêixis em narrativas ficcionais? Para responder a esse questionamento, poderíamos citar várias peculiaridades constitutivas do processo de escrita desses textos. Certamente seria uma caracterização interessante. Contudo, entendemos que, para melhor compreensão do fenômeno linguístico aqui investigado, se faz necessário atentar especialmente para a construção de sentido realizada na leitura.

Compreendemos que, pelo fato da referência no texto ficcional ser particularmente produtiva, muitos fatores merecem atenção especial numa pesquisa realizada a partir de uma perspectiva linguística. Em nosso trabalho, elegemos o fenômeno dêitico, focando especialmente na dêixis memorial. Trabalhamos com a realização dêitica nas distintas instâncias enunciativas das narrativas ficcionais com o objetivo de verificar como o processo dêitico é construído de maneira distinta nas narrativas ficcionais a partir da noção de espaços memoriais.

Dessa forma, preferimos destacar que as narrativas ficcionais não requerem apenas uma forma distinta de escritura, mas também uma leitura diferenciada em vários aspectos, como nas mudanças de centro dêitico. Podemos compreender melhor este aspecto sobre a relação entre ficção e elementos dêiticos com o estudo de Fonseca (1992) que apresenta a concepção de dêixis fictiva, destacando as noções de tempo, espaço e lugar. Contudo, o espaço da memória não cabe no conceito clássico de dêixis fictiva e é exatamente esse espaço que exploramos aqui.

\section{Os espaços memoriais}

Em nossa pesquisa de mestrado, analisamos os processos dêiticos em contos e verificamos que a dêixis memorial nesses textos contribuía para a construção de sentido de uma "ilusão" referencial, mudando da perspectiva do narrador para a do personagem ou mesmo do leitor. Esse deslocamento de perspectiva é uma ferramenta muito produtiva na construção do mundo ficcional, que está diretamente ligado aos campos dêiticos (HANKS, 2008), funcionando como um instrumento que guia o olhar do leitor e o conduz pelo tempo e pelo espaço.

Dessa forma, não é necessário que uma narrativa se inicie com a descrição do cenário (como costuma ocorrer nos contos de fadas, por exemplo) para que o leitor seja conduzido para o interior da história, ou seja, posicione-se dentro da narrativa. A perspectiva dêitica é eficaz em colocar diante dos olhos do leitor o mundo ficcional.

Afirmamos, assim, que a narrativa ficcional propicia vários espaços memoriais, ou seja, esses textos possibilitam memórias enunciativas sob várias perspectivas: a dos personagens (pode ser apenas um deles ou vários), a do narrador (seja ele personagem ou não) e a do leitor. Esse fenômeno ocorre nas narrativas ficcionais porque essas demandam a criação de uma cenografia fora do "mundo real", mas não podem retirar-se por completo dele.

Assim, é o seu caráter fictivo, o mundo representado, que favorece não apenas a delegação de vozes, mas o processo de construção de espaços memoriais nas instâncias enunciativas (FIORIN, 1996). É um mundo enunciativo, ao mesmo tempo, tão distante do mundo empírico, mas que o toma por base. E, nesta relação ambígua, o leitor está no centro. Sobre essa relação entre o ficcional e o real, Segal (1995) afirma que: 
Ao ler um texto ficcional, a maiorias dos leitores pensa que está dentro da história, e de modo impaciente e hesitante espera para ver o que acontecerá em seguida. Os leitores adentram as histórias e as vivenciam de modo vicário. Eles se sentem felizes quando boas coisas acontecem, preocupam-se quando os personagens estão em perigo e podem mesmo chorar, quando ocorre alguma desgraça. (SEGAL, 1995, p. 14-15). ${ }^{2}$

Considerando essa projeção do leitor no texto, definimos espaços memoriais a partir da perspectiva de Fonseca (1992), que considera a ocorrência de uma projeção das coordenadas dêiticas numa enunciação fictiva, gerando outro eu-aqui-agora, o que nos permite falar em outros espaços de memória, dentre eles o dos personagens, uma memória fictiva. Defendemos que esses espaços memoriais correspondem ao centro dêitico (ZUBIN; HERWITT, 1995) de cada instância enunciativa.

Dessa forma, em nossa análise, observamos elementos dêiticos que se inserem numa dada instância enunciativa que podem ou não estar acessíveis ao leitor de acordo com o cotexto (indícios textuais) ou o contexto (conhecimento socialmente compartilhado).

Assim, o que nomeamos como espaços memoriais consiste em uma noção enunciativa, a partir de uma concepção sociocognitivo-discursiva dos processos referenciais, cujo conceito se relaciona diretamente ao fenômeno da dêixis memorial.

Apothéloz (1995) afirma que os dêiticos memoriais são aqueles capazes de referir em ausência devido ao conhecimento compartilhado entre os interlocutores. A partir desse conceito, compreendemos que o valor ostensivo destes elementos, enquanto dêiticos, dá-se pelo fato de eles também apontarem para o espaço da memória e não para a situação enunciativa ou para partes do texto. Neste caso, o espaço da memória é um espaço de memória compartilhada. Geralmente partilhada numa esfera maior, de ordem social, cultural.

O que ocorre nas narrativas ficcionais é que esse espaço de memória mais amplo é apenas um deles. Vale salientar que os espaços memoriais não se configuram como categorias isoladas e excludentes. Muitas vezes os limites são fluidos, não marcados pontualmente, produzindo nuances que enriquecem a construção da narrativa.

\section{A dêixis memorial no texto ficcional}

Os dêiticos memoriais costumam ser identificados na materialidade textual através de SN demonstrativos ${ }^{3}$. É o que ocorre no exemplo a seguir:

(1) Quer dizer que a senhora está mandando meu presente praquela parte. (ANDRADE, 2006).

O leitor, de uma forma geral, não terá dificuldades em compreender o sentido da expressão em destaque, e essa compreensão é possível pelo seu conhecimento de mundo que lhe permite identificar que a expressão em destaque substitui outra menos polida. Da mesma forma, é provável uma criança, que não tem tal expressão pouco polida inclusa em seu vocabulário ou não presencia os adultos de sua convivência fazerem uso dela, não compreenderá o exemplo anterior.

\footnotetext{
${ }^{2}$ When reading fictional text, most readers feel they are in the middle of the story, and they eagerly or hesitandly wait to see what will happen next. Readers get inside of stories and vicariously experience them. They feel happy when good things occur, worry when characters are in danger and may even cry, when misfortune strikes.

${ }^{3}$ Embora também os SN definidos possam ter um uso dêitico memorial.
} 
Haveria um questionamento do tipo "Para onde a senhora mandou o presente?". Questão que certamente não ocuparia um leitor adulto.

Contudo, verificamos que este é apenas um dos usos possíveis da dêixis memorial nas narrativas ficcionais, ou seja, uma memória não fictícia é apenas um dos possíveis espaços para onde uma expressão dêitica memorial pode apontar nesses textos. Pois, como não temos apenas um espaço memorial, mas espaços memoriais.

Ciulla (2008) faz menção a dêiticos da pseudomemória, fenômeno definido como

[...] fingir ou forjar uma memória, isto é, é como se o escritor apontasse para um conhecimento supostamente compartilhado com o leitor, que, na verdade, nada sabia antecipadamente e precisa explorar esse novo espaço desconhecido da leitura, construindo referentes e significados. (CIULLA, 2008, p.111).

Nossa proposta com os espaços memoriais difere do que a autora chama de pseudomemória por incluir uma memória compartilhada entre os personagens que pode ou não ser recuperada pelo leitor. Não entendemos como um apenas como um falseamento, mas como possibilidades construtivas diferentes.

Em resumo, quando relacionamos os espaços memoriais ao processo de construção da referência nestes, encontramos quatro possibilidades de dêiticos memoriais na narrativa ficcional. Nas três primeiras, o dêitico memorial aponta para um espaço memorial fictivo, que é composto pelas memórias das três instâncias enunciativas (FIORIN, 1996): o eu narrador (primeiro grau da debreagem interna), o eu a quem o narrador dá a palavra (segundo grau da debreagem interna), que, pode, por sua vez, repetir o processo dando voz a outro eu (terceiro grau da debreagem interna).

A classificação clássica da dêixis memorial trata apenas da última possibilidade, ignorando as diferenças de sentido ocorridas quando a memória é construída por uma estratégia narrativa e a diferenciação do fenômeno de acordo com a instância enunciativa. Assim, a reboque da noção de espaços memoriais, temos os dêiticos memoriais fictivos, que, nas narrativas ficcionais, completam o quadro dos dêiticos memoriais.

Dessa forma, resumimos no quadro a seguir nossa proposta de identificação das diferentes possibilidades de uso dos elementos dêiticos memoriais nas narrativas ficcionais.

Quadro 1 - Usos dêiticos memoriais em narrativas ficcionais

\begin{tabular}{|l|l|}
\hline \multirow{2}{*}{ Dêiticos memoriais fictivos } & Na primeira instância enunciativa \\
\cline { 2 - 2 } & Na segunda instância enunciativa \\
\cline { 2 - 2 } & Na terceira instância enunciativa \\
\hline \multicolumn{2}{|c}{} \\
Dêiticos memoriais não-fictivos
\end{tabular}

Fonte: Elaborado pela autora. 
Vejamos agora a questão da dêixis memorial fictiva e suas realizações nas três instâncias do texto narrativo. Apresentamos alguns exemplos do corpus de nossa pesquisa com o intuito de demonstrar os fenômenos observados.

\section{A dêixis memorial fictiva}

O leitor, diante de uma narrativa ficcional, realiza uma espécie de concessão construtiva, ou seja, em função de uma colaboração imaginativa. Há a consciência, por parte do leitor, de que tais textos devem ser construídos referencialmente dentro de uma cenografia, um mundo da história que não pode, mesmo que faça uso de largas e detalhadas porções descritivas, apresentar todos seus elementos de forma explícita.

Apesar da colaboração do leitor em toda leitura, ela é exigida em um grau bem mais alto nas narrativas ficcionais, pois, conforme afirma Segal (1995), tanto leitores quanto escritores costumam se imaginar dentro do mundo que constroem nas narrativas de tal forma como se, de fato, fizessem parte da história. Trata-se de uma espécie de projeção experimentada pela mudança dêitica, em que o leitor "toma uma posição cognitiva dentro do mundo da narrativa e interpreta o texto a partir dessa perspectiva" (SEGAL, 1995, p.15). Assim, esse texto pode explorar não somente uma memória compartilhada socialmente (que corresponde à concepção corrente de dêixis memorial), mas uma memória construída pelo exercício de ficcionalidade. Esse fenômeno pode produzir diferentes efeitos de sentido nas três instâncias enunciativas constitutivas desses textos. Vejamos os exemplos:

(2) Se o leitor conhece um homem forte, mas muito forte mesmo, imagine uma pessoa duas vezes mais forte, e terá uma vaga ideia desse gigante que veio andando até nós, botando ódio pelos olhos e espetacularmente bêbado. (CAMPOS, 1995).

O trecho apresentado em (2) é um exemplo no qual o conhecimento é compartilhado na primeira instância enunciativa, isto é, as representações textuais do autor e do leitor configuram o centro dêitico. O espaço da memória é de ordem fictiva, ou seja, a construção ficcional fornece subsídios para esse conhecimento comum. Aqui, a construção de uma memória textual aparece reforçada inclusive pelo verbo utilizado, imaginar, usado no imperativo, numa enunciação em que o leitor é explicitamente marcado no texto. Além disso, os indícios textuais são apresentados em gradação para alimentar a ação que lhe é proposta: imaginar. $\mathrm{O}$ exercício fictivo se verifica no narrador (que se mostra como figura de autor), que tenta transmitir ao seu leitor uma imagem que faz parte da narrativa e que se apresenta como a recordação de uma experiência vivida por ele. Para a construção dessa imagem, o autor apela primeiro para o conhecimento de mundo do leitor ("Se o leitor conhece um homem forte"), que deve ser exagerado ("muito forte mesmo") até chegar a algo incomum ("uma pessoa duas vezes mais forte") que seria o mais próximo ("uma vaga ideia") da imagem original ("esse gigante"), a visualização termina com a caracterização da forma como o indivíduo foi até o narrador e seu amigo ("botando ódio pelos olhos e espetacularmente bêbado").

Podemos observar que "esse gigante" era uma memória apenas do narrador e que ele compartilha com o leitor através da narrativa fornecendo os indícios textuais para que o leitor construa no seu imaginário uma imagem que corresponda, ainda que sem exatidão, à imagem da memória do narrador. Trata-se de um compartilhamento de conhecimentos que ocorre na primeira instância enunciativa a partir da construção narrativa. 
Na segunda instância, encontramos a dêixis memorial explorada fictivamente de outra maneira, conforme vemos no exemplo a seguir.

(3) E cada vez mais forte, corado, gordo e saudável. "Saudável, eu?" - reage, como a um insulto: "Minha Santa Efigênia! Passei a noite que só você vendo: foi aquele bife que comi ontem, não posso comer gordura nenhuma, tem de ser tudo na água e sal". (SABINO, 1995).

A crônica da qual retiramos o exemplo anterior é apresentada por um narradorpersonagem que é amigo do personagem principal, um sujeito com mania de doença. No trecho acima, as falas do protagonista são marcadas por aspas, separando-as das avaliações do narrador sobre o tal. Não fica claro se, especificamente no diálogo aí mostrado, o interlocutor é o narrador ou outro amigo do "doente", mas o que podemos inferir é que o você que participa da conversa havia jantado com o personagem na noite anterior ("ontem") e sabe por isso que este comeu um bife (que não fora preparado "na água e sal") e, por isso, pode ser referido nesta enunciação como "aquele bife", pois se trata de uma memória compartilhada pelos personagens.

Notemos que, se não houvesse esse conhecimento comum entre os personagens, o elemento dêitico aquele seria provavelmente substituído pelo indefinido um, e a afirmação seguinte sobre a preparação dos alimentos adequada para o protagonista serviria para que seu interlocutor soubesse como era o bife mencionado. Contudo, ocorre o inverso, a memória de como foi o jantar de ontem em oposição ao que ele afirma ser-lhe adequado é que explica ao seu amigo o fato de o personagem ter passado a noite mal.

A terceira instância enunciativa, ou seja, uma segunda debreagem, tem uma ocorrência menor que as duas primeiras, mas também possibilita novas possibilidades de efeitos de sentido a partir de uma memória fictiva. Vejamos o exemplo:

(4) - Pra você depois contar pros seus amigos, né? ...

- Contar pros meus amigos? ...

- Claro - ela disse. - Lá no bar, lá na sua rodinha, depois de tomar umas tantas, você vai dizer: "Sabem aquela minha sobrinha, a Daniela?". (VILELA, 2002).

Este conto constrói-se como um diálogo entre uma sobrinha adolescente que visita, no hospital, o tio que se recupera de uma cirurgia (segunda instância enunciativa). Há poucas e breves enunciações do narrador (primeira instância enunciativa), geralmente restritas a alguma informação sobre o estado ou os movimentos dos personagens. No exemplo em tela, encontramos a terceira instância (marcada por aspas) num breve trecho ficcional criado por uma personagem dentro da narrativa em si. É apresentado outro cenário (um bar) em outro tempo (quando o tio já estivesse recuperado) no qual a personagem Daniela não está presente, mas estão os amigos do tio, que é tomado como personagem que enuncia a frase entre aspas, logo, ocorre uma nova debreagem de terceiro grau, visto ter sido instaurada pelo actante já debreado em segundo grau (a personagem Daniela).

Nesta pequena fabulação, a ilusão de presença é da personagem (e não apenas do leitor, mas ainda deste), que finge visualizar uma cena, como se a testemunhasse. Quando a personagem Daniela acusa o tio de querer contar vantagem aos amigos, ele a questiona e ela visualiza (e traz aos olhos do tio - e do leitor!) a cena: O tio em um bar, numa rodinha de amigos, depois de beber um pouco (ou muito), começar a falar sobre ela. 
Nesta fala imaginada, o fato de Daniela ser mencionada primeiramente como "aquela minha sobrinha" remete a uma memória compartilhada entre os personagens instaurados na terceira instância enunciativa. Assim o leitor infere que os amigos do tio sabem da existência de Daniela seja por conhecê-la pessoalmente, seja porque ele já a havia mencionado em outras ocasiões. Logo, a expressão "aquela minha sobrinha" aponta para uma memória fictiva que se realiza na terceira instância enunciativa.

Obviamente, também ocorrem nestes textos os exemplos clássicos de dêixis memorial que apontam para uma memória socialmente compartilhada, independente das instâncias enunciativas nas quais se apresenta. Estes casos, denominamos como dêiticos memoriais não-fictivos, por apresentar uma referência memorial cuja base informacional é amplamente compartilhada em distinção às três primeiras categorias que constroem sua memória a partir da construção ficcional.

\section{A dêixis memorial não-fictiva}

Como já afirmamos, nem todo processo dêitico memorial construído em textos ficcionais será fictivo. Assim sendo, os dêiticos memoriais não-fictivos podem ser encontrados nas narrativas ficcionais em qualquer uma das três instâncias e apontarão sempre para uma memória compartilhada socialmente, ou seja, esta não é uma memória fictiva, como podemos observar no exemplo seguinte.

(5) Pois fique sabendo que é esse o instrumento preferido do Anjo Decaído, aquele!, disse engrossando a voz e espetando com a mão livre dois dedos na testa. (TELLES, 1986).

No exemplo (5), temos um diálogo entre personagens (segunda instância enunciativa), contudo, a referência a um anjo decaído não é de uma informação compartilhada apenas entre as personagens, mas de conhecimento comum, diferente do que ocorre com o dêitico memorial fictivo na segunda instância, em que a dêixis memorial não apenas se apresenta na segunda instância enunciativa, mas aponta para um espaço memorial fictivo, isto é, um espaço restrito à ficção.

Observamos, porém, que mesmo em ocorrências de dêixis memorial não-fictiva, podemos encontrar algumas peculiaridades interessantes nas narrativas ficcionais. Analisemos o exemplo a seguir.

(6) Duvido que alguém me diga onde fica Andorra. A última pessoa a quem perguntei, me disse que ficava nos limites de Aznavour. Pois fica é logo aqui, encravada entre a França e a Espanha, um paisinho de nada, vê quem pode. E fez aquele sucesso todo no Festival da Canção. (SABINO, 1995).

A expressão em destaque no exemplo (6) aponta para um conhecimento compartilhado socialmente através da forma mais prototípica dos dêiticos memoriais, o SN demonstrativo, por isso identificamos como uma ocorrência de dêixis memorial não-fictiva. Contudo, destacamos um detalhe: se compararmos os exemplos (5) e (6), a referência a um "anjo decaído" nos parece acessível a um grupo muito maior que o "sucesso" de Andorra num dado festival musical.

Salientamos, contudo, que a referência a um sucesso do Festival da Canção pode não ser acessível a um grande grupo na atualidade, mas provavelmente o era quando esta crônica foi escrita originalmente para um jornal ou uma revista, antes de ser eternizada sob forma de livro. 
Logo, o que queremos destacar aqui é a relação entre a construção referencial e a cena genérica (MAINGUENEAU, 2006) na qual se insere. O aspecto a ser considerado na análise do exemplo (6) é que, por se tratar de uma crônica, sua base é o cotidiano. Não podemos recuperar inteiramente um cotidiano tão distante temporalmente do hoje. Ora, o cotidiano é dêitico!

\section{Conclusão}

O texto ficcional costuma ser objeto de estudo principalmente de pesquisas ligadas aos Estudos Literários. Contudo, para além das questões estilísticas, há uma grande variedade de fenômenos linguísticos que encontram nesses textos condições peculiares, a questão da construção referencial é, sem dúvida, um desses fenômenos. Nossa pesquisa se deteve aos elementos dêiticos, em especial os dêiticos memoriais. Nosso principal resultado foi a concepção de dêixis memorial fictiva relacionada aos espaços memoriais (correspondentes ao centro dêitico de cada instância enunciativa) que se contrapõe a uma dêixis memorial não-fictiva, embora ainda nessa as questões enunciativas da ficcionalidade deixem o seu tom. Assim, destacamos que não empreendemos a realização de um exercício classificatório descritivo, prescritivo, mas um esforço em reconhecer distintas nuances dentro do complexo processo de referenciação nas narrativas ficcionais.

\section{REFERÊNCIAS}

ANDRADE, C. D. Outro presente para a senhora. In: TUFANO, D (org). Antologia da crônica brasileira: de Machado a Lourenço Diaféria. São Paulo: Moderna, 2006. p. 83-86.

APOTHÉLOZ, D. Papel e funcionamento da anáfora na dinâmica textual. In: CAVALCANTE, M. M.; BIASI-RODRIGUES, B.; CIULlA, A. (Orgs.). Referenciação. São Paulo: Contexto, 2003.

CAMPOS, P. M. Salvo pelo Flamengo. In: Para gostar de ler. Vol 3. Crônicas. Ed. Ática: São Paulo, 1995. p. 18-21

CIULLA E SILVA, A. Os processos de referência e suas funções discursivas: o universo literário dos contos. Tese de doutorado em Linguística - Universidade Federal do Ceará, Fortaleza, 2008.

FIORIN, J. L. As astúcias da enunciação. São Paulo: Ática, 1996.

FONSECA, F. I. Deixis, Tempo e Narração. Porto: Fund. Eng. António de Almeida Fonseca, 1992.

FRASER, T.; JOLY, A. Le systeme de la deixis. Lille: Modèlles linguistiques, 1980.

HANKS, W. F. Língua como prática social: das relações entre língua, cultura e sociedade a partir de Bourdieu e Bakhtin. São Paulo: Cortez, 2008.

MAINGUENEAU, D. Discurso literário. São Paulo: Contexto, 2006.

SABINO, F. Obrigado, doutor. In: Para gostar de ler. Vol 5. Crônicas. Ed. Ática: São Paulo, 1995. p. 35-37.

SEGAL, E. M. Narrative comprehension and the role of deictic shift theory. In: DUCHAN, F. J; BRUDER, G. A.; HEWIT, L. E. Deixis in narrative. New Jersey: Lawrence Erlbaum Associates, 1995. p. 19-60.

TELLES, Lygia Fagundes. Antes do baile verde. 9. ed. Rio de Janeiro: Nova Fronteira, 1986.

VILELA, Luiz. A cabeça. Cosac \& Naify - São Paulo, 2002. 
ZUBIN, D.A.; HEWITT, L. E. The deitic center: a theory of deixis in narrative. In: DUCHAN, F. J; BRUDER, G. A.; HEWIT, L. E. Deixis in narrative. New Jersey: Lawrence Erlbaum Associates, 1995. p. 129-155.

Recebido em 21/02/2018. Aceito em 06/06/2018. 